considerable attention. Some of this exhaustive material on producing and wearing indigenous clothing is available in other texts. Yet, Hendrickson's book fairly bulges with thoroughly researched information that pulls the whole cultural package together in one source. I for one, read and reread the section devoted to clothing and the body as I had long wondered about modesty, bedtime, and "pajamas" in the highlands.

In sum, I was fascinated by Weaving Identities in the sense that it may serve as a primer of Mayan weaving and traje. Along the way, Hendrickson does a fine job of demonstrating just how intricately wedded the meaning of clothing is to the Mayan life cycle and to personal and ethnic identity. It may be, however, that the exquisite detail the author provides will be a handicap in terms of the wider dissemination of the book. Although Weaving Identities will appeal both to textile specialists and to Mayanist ethnographers, it is decidedly not for classroom use, and indeed, I doubt that this was its purpose. Although the book has been discussed as an ethnography, my sense is that its emphasis on material culture sets it apart. Its orientation is not the Tecpanecos, but the textiles they weave and the clothes they wear. The author's interests do not lie in telling stories or providing case studies. Her passion is the cloth itself. In spite of the intimate tone with which the book is written, its rationale was not to search out ethnographic drama in the usual places. Readers in search of linkages between traje and gender, or analysis of the aching impoverishment of weavers and wearers should seek out other sources.

Weaving Identities sets out to describe carefully the production of clothing as an essential part of the identify of the people of Tecpán. As such, it establishes itself as a marvelously fertile resource and should be in a prominent place on one's shelf of books on textiles. Some readers may be frustrated by Hendrickson's narrow focus on traje, but those who are seeking an encyclopedic examination of this topic will be richly rewarded.

\title{
A Place in the Rain Forest: Settling the Costa Rican Frontier. Darryl Cole-Christensen. Austin: University of Texas Press. 1997. 243 pp.
}

\section{Reviewed by Philip D. Young, Department of Anthropology, University of Oregon, Eugene}

In 1954, Darryl Cole-Christensen and his family moved from California to the Valley of Coto Brus, the "South Frontier" of Costa Rica. At the time this area was in the earliest stages of settlement, completely undeveloped. There was a small, struggling group of Italian settlers at San Vito, and a few Costa Ricans. More were to come later. The area was covered in primary humid tropical rain forest. The Cole-Christensens and the other settlers all came with the same dream--to turn the rain forest into successful, profitable farms. Today the rain forest is gone from the Coto Brus, replaced mostly by coffee farms and pasture.

Cole-Christensen and his family developed their farm over a period of 25 years before returning to the United States. The farm, Finca Loma Linda, remains theirs and is still a working farm. For more than a decade now, however, it has served as a research site for 
studies in tropical ecology, biology, and agronomy conducted by faculty, students, and researchers from several universities in the U. S. and Costa Rica.

Costa Rica's rate of deforestation of primary forest, estimated at between four and five percent annually during the 1980s, was for many years among the highest in Latin America. Geographer Valery Terwilliger of the University of Kansas estimates that between 70 and 80 percent of Costa Rica's forests have been cut since the 1960s. The Pacific side of Costa Rica is now virtually devoid of primary forest except in the highest elevations of the Talamanca Range. Much of the cleared land has been converted to coffee farms and pastures, a small part to crop land. The rate of deforestation has slowed during the past two decades, in no small measure due to the efforts of the Costa Rican government and conservation organizations. Costa Rica now has about 11 percent of its territory under strict protection and roughly another 10 percent in forest reserves and protected zones that permit limited exploitation.

The book under review does not provide any of this information nor does it place the settlement of the Coto Brus within this broader context, yet it is an account of this process of deforestation. And a passionate, account it is. The author's literary talents move the reader to feel the pain, the weariness, the desperation and frustration, the joy in small successes, of those who settled this last Costa Rican frontier on the Pacific slopes of the Talamanca Range near the Panamanian border. Some readers will also feel the pain of the rain forest and the earth itself as this natural ecosystem, a long time evolving, is stripped away in a few short years, as yet another segment of western humanity makes yet another attempt to tame and control nature.

This chronicle of the settlement and transformation of the South Frontier is told with hindsight and considerable philosophical introspection concerning the process. The author makes no claim that this is a scientific book, and it is not. There are no references cited in the text and there is no bibliography of sources consulted. This does not mean it is a bad book. It is a fascinating personal account of the author's 25 years in the area. With elegant literary style (Nigel Smith compares the book to the works of Aldo Leopold and Thoreau), Cole-Christensen examines the multifaceted interplay of relationships between settlerfarmers and the humid tropical rain forest environment, and reflects upon the environmental consequences of what the settlers, in their ignorance, wrought. Many passages have a lyrical quality about them; metaphor is used to good advantage in helping the reader relate both to the trials and tribulations of the settlers, and the environmental issues raised by trying to turn rain forest into farms.

We may agree with much of what the author says about the humid tropics as an ecosystem (sensu laxu) and about the difficulties and the consequences of radical alteration of this ecosystem to meet perceived human needs; but none of what ColeChristensen says about human-environment relationships is likely to be new information for the readers of the Journal of Political Ecology. For the literate public, however, this very personal account of one family's prolonged effort to learn from early mistakes and come to terms with tropical ecosystems in a harmonious way, may very well convey the message more effectively than a shelf full of scientific treatises on tropical rain forest ecology. But if this premise is true, then it would seem that we need to attend very carefully to the content of the messages being conveyed here.

Cole-Christensen alleges that in the 1950s almost nothing was known about rain forest ecosystems and perhaps even less was known about farming in the humid tropics. In both instances, it is certainly true that we know more now than we did then, in the sense of formal scientifically arrived at knowledge. Indigenous peoples had successfully farmed 
the humid tropics of the Americas long before the European invasion, however, and some groups continue to do so. So, in an informal sense, the knowledge was already available, but as many of us know, the white man has a real penchant for re-inventing the wheel--and often not doing a good job of getting it round. In fairness, there was no talk even in scientific circles of the value of indigenous knowledge systems back in the 1950s. Even anthropologists, the consummate documenters of these bodies of accumulated experiential knowledge, were not yet examining this knowledge for the range of potential alternatives that it might provide to the less sustainable practices of modern society.

The author spends much time on his own experiences, but he does speak also of the other settlers, especially the Costa Ricans and the Italians. Freely admitting early errors of judgement (attributed to ignorance) that had devastating impacts on the land and the ecosystem of which the land was only a part, Cole-Christensen sets about a relatively systematic process of experimentation in order to learn how to farm in this seemingly unforgiving environment. But, curiously, this is an age-old lesson, one learned many times by indigenous peoples throughout the tropical world. Even more curious is that in the 1950s, at the same time that Costa Ricans, Italians, and a handful of expatriates like ColeChristensen were trying to learn how to successfully farm in the Coto Brus, Nglbe (GuaymR) families from Chiriqui Province in Panama were colonizing this same area, yet there is no mention of them anywhere in the book. Interestingly, the Nglbe form of slashand-burn agriculture is well suited to productive subsistence farming in the rain forest.

But the non-Nglbe settlers of the Coto Brus wanted more than mere subsistence from the land, as Cole-Christensen explicitly acknowledges: "After basic food necessities were met by some production from the land--subsistence provided--it remained to produce a cash income, for subsistence, by its very nature, is not a satisfactory way of life" (p. 21). This is undoubtedly an accurate representation of the perspective of the majority of the settlers. It is also a particularly Western capitalist point of view. Subsistence has been a satisfactory--and satisfying--way of life for countless indigenous cultures over the centuries. And although it would be an exaggeration to attribute a conservation ethic to all native cultures, it is certainly the case that the subsistence-based societies of the world have done considerably less damage to environment than have modern capital-based societies. But the market is now a global market, the economy a global economy, and all those formerly subsistence-based societies show the scars of past encounters and the open wounds of fresh encounters with this global system.

It seems that from the very beginning, the author, and presumably his family as well, were of two minds about what was to become an endeavor of decades: the attempt to turn the rain forest into a productive and profitable farming operation. On the one hand, it is clear that the author recognized the magnificence of the rain forest and sensed its enormous ecological complexity and systematicity, and he speaks of this in terms most eloquent. On the other hand, in equally eloquent terms he speaks of the struggle of the would-be farmer to control nature. Here the specter of Frederick Jackson Turner's spirit of the American frontier rises up, and it is unsettling.

We know we cannot turn the clock back--and most of us would not want to were it to mean, as it most assuredly would, that we would have to forego many of the amenities of modern life--but surely we do need to learn how to live more lightly on this earth, how to live more in harmony with those natural aspects of the ecosystems of which we are an integral part. This is one of the strongest messages of this book, one that is conveyed in a variety of ways by Cole-Christensen in this emotionally moving and reflective account of carving farms out of the Costa Rican rain forest. 
Yet there are also some rather disturbing statements in this book that, sadly, betray a Western set of values that foregrounds control over nature, in contrast to the prevailing values of the majority (if not all) Native American groups in the American tropics that foreground living in harmony and balance with nature.

This book contains no maps, a serious omission for those unfamiliar with Costa Rica. However, with a little searching, I found that Finca Loma Linda has a web site - < http:// www.squaw.com/summer_site/summer/index.htm>-which does contain both the location of the farm on a map of Costa Rica, and a map of the farm layout (as well as other information).

In the final analysis, this book conveyed mixed messages. The author speaks of both harmony with nature and control over nature. Finca Loma Linda has been converted to meet the needs of scientific research on farming in the tropics and on systemic relations in successional and primary forest (about a third of the farm's land deliberately was left from the beginning in primary forest). This is laudable, but it still represents an effort at control over nature. It does not appear that any efforts are being made to incorporate the lessons that indigenous knowledge systems have to offer.

This book is well worth reading, but to me its message is still very Western in the values that are espoused. Would that it were otherwise.

\title{
Performing Dreams: Discourses of Immortality Among the Xavante of Central Brazil. By Laura R. Graham. 1995. University of Texas Press. xiv, 290 pp.
}

\author{
Reviewed By Debra Picchi, Department Of Anthropology, Franklin \\ Pierce College, Rindge, New Hampshire
}

Graham's engagingly written book recounts in epic terms the ritual performance of a dream-myth by a Brazilian Indian community. Organized so as to lead the reader through an initial description of a Xavante Indian leader's dream peopled by mythic beings, then on to a description and analysis of the various expressive forms used by these people, and finally to the preparation and performance in the village plaza of the dream, this tour de force builds to a climax that cannot fail to affect even those whose area is not Brazilian Indians or mythology.

The book is based on research done between 1981 and 1991 with the Xavante Indians of the Pimentel Barbosa Reservation in Mato Grosso, Brazil. It is made up of seven chapters, each of which includes discussions about what life is like for these Indians. These highly readable sections alleviate the sometimes dense theoretical sections, which although well written, can sometimes pose a challenge for those unacquainted with the study of discourse practices.

Chapter 1 introduces Warodi, the Xavante elder whose dream is at the heart of the book. It also explains the idea of polyvocal discourse, is the way in which these Indians recount myths and dream. This type of discourse involves a number of people who repeat, 